\title{
Dietary patterns and home food availability during emerging adulthood: do they differ by living situation?
}

\author{
Melissa Nelson Laska*, Nicole I Larson, Dianne Neumark-Sztainer and Mary Story \\ Division of Epidemiology and Community Health, University of Minnesota, 1300 South 2nd Street, WBOB Suite \\ 300, Minneapolis, MN 55454-1015, USA
}

Submitted 11 March 2009: Accepted 8 June 2009: First published online 20 August 2009

\begin{abstract}
Objective: The objective of the present work was to cross-sectionally examine and compare dietary behaviours and home food environments by young adults' living situation.

Design: Using data from Project EAT (Eating Among Teens)-II, a large diverse youth cohort originally sampled in Minnesota, linear regression was used to examine self-reported meal frequency, dietary intake and home food availability outcomes by living situation (i.e. living with parents, renting an apartment/house or living on a college campus).

Subjects: Young adults ( $n$ 1687), mean age $20 \cdot 5$ years.

Results: Results suggested that young adults living with their parents or in rented apartments/houses had less frequent meals, poorer dietary intake and less healthy home food availability compared with those living on campus. These findings were evident even after controlling for sociodemographic factors (e.g. race/ ethnicity, socio-economic status), particularly among females.

Conclusions: Although few emerging adults consume diets that are consistent with national recommendations, those living with parents and in rented apartments/houses may represent particularly at-risk groups. These differences in dietary factors across living situations appear to exist beyond the sociodemographic differences in these populations. Effective nutrition and healthy eating promotion strategies are needed for young adults.
\end{abstract}

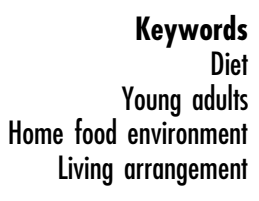

'Emerging adulthood', typically defined as ages 18-25 years, is a unique developmental period when young people's independence and autonomy are increasing. It is also a high-risk time for adverse health behaviours ${ }^{(1,2)}$. Previous research has highlighted the need for health promotion strategies for this age group, such as tobacco cessation and other efforts aimed at promoting healthy lifestyles ${ }^{(3)}$. However, scant attention has focused on nutrition and healthy eating promotion for young adults. These emerging adult years may be a particularly important time to focus on nutrition-related issues, especially given the rapid increases in obesity prevalence at this age ${ }^{(4)}$, as well as the impact that excess weight gain in early adulthood may have on long-term health ${ }^{(5,6)}$. The transition to adulthood is also a key developmental age when long-term weight behaviour patterns may be established $^{(1)}$. Although some existing evidence suggests that adverse shifts in diet and weight-related factors likely occur between adolescence and adulthood, few studies to date have described these changes in detail ${ }^{(1)}$.

Furthermore, while a limited number of studies have examined differences in dietary intakes among US college students by living situation (i.e. living either on or off campus) ${ }^{(7,8)}$, to our knowledge no studies to date have examined these differences within a more generalizable young adult population, including those who represent a range of lifestyle characteristics (i.e. those who attend college, as well as young adults who are not college students) and living situations (those living on their own, with parents and/or on college campuses). Previous research among other age groups, such as children and adolescents, has suggested that living situations and various facets of the home environment may have an important impact on meal patterning and dietary intake and may be important factors to consider in designing health promotion strategies ${ }^{(9-12)}$. In order to build current knowledge and inform the possible development of nutrition interventions for young adults, there is a substantial need for research that explores how dietary patterns may vary across different living situations of young adults and how home environment characteristics may influence dietary intake among this age group.

Thus, the objective of the present work was to examine cross-sectional differences in dietary intake, meal patterns 
and home food availability among emerging adults by living situation (i.e. living in a rented apartment or house, living with parents or living on a college campus) using data drawn from a large, diverse, population-based cohort of youths. The research assessed: (i) the prevalence of diet-related factors by living situation; as well as (ii) disparities in dietary factors independent of known sociodemographic differences (e.g. according to socioeconomic status (SES) and race/ethnicity) in diet.

\section{Methods}

Data for the present cross-sectional analysis were drawn from Project EAT (Eating Among Teens)-II, a populationbased follow-up study ${ }^{(13)}$. At baseline (1998-9), 3074 young people were surveyed in Minnesota high schools (mean age $15 \cdot 8$ years). Five years later (2003-4), participants were mailed a follow-up survey and FFQ. The sample for the current study consisted of 750 males and 937 females who completed both mailed assessments (mean age 20.5 years, range 18-23 years). A majority of the cohort completed the 5-year follow-up survey several years after graduating from high school. Study protocols were approved by the University of Minnesota Institutional Review Board. Additional study design details are reported elsewhere ${ }^{(13,14)}$

\section{Measures}

\section{Living arrangement}

Living arrangement was self-reported on the Project EATII survey. Living arrangement was defined as where the participant lived for a majority of the time in the past year, including: rented apartment or house, parent's home or on campus. Campus options included residence hall and fraternity/sorority; these were collapsed due to the relatively low prevalence of students living in fraternity/ sorority housing. Participants indicating other types of living situations, such as 'own a house' ( $n$ 48) or 'other' ( $n$ 49), were not included in these analyses due to small sample sizes.

\section{Dietary intake}

The Youth and Adolescent FFQ was used to assess usual past year intake of a wide range of foods and nutrients $^{(15-17)}$. Dietary intakes (servings/d) of fruits, all vegetables (excluding French fries), dark green and orange vegetables only, Ca-rich foods, whole grains (excluding chips) and soft drinks were measured. Specific foods and beverages included in each category have been described elsewhere ${ }^{(14,18)}$. Ca intake, total energy and the percentages of total energy intake from total fat, saturated fat and trans fat were also assessed. Research describing the reliability and validity testing of this questionnaire has been detailed extensively in previous publications ${ }^{(15-17)}$.

\section{Eating patterns}

Meal frequencies were assessed using the EAT-II survey. Participants were asked separate items for: how often they ate breakfast, lunch and dinner during the past week (response categories included never, 1-2d, 3-4d, 5-6d and every day); how often they ate at a fast-food restaurant (like McDonald's, Burger King, Hardee's, etc.) in the past week (response categories included never, 1-2 times, 3-4 times, 5-6 times, 7 times and $>7$ times); and how often they snacked (ate between meals) yesterday (response categories included none, 1 time, 2-3 times, 4-5 times and $>5$ times). Test-retest reliability for these items was evaluated at baseline (1998-9) of Project EAT (breakfast, $r=0 \cdot 77$; lunch, $r=0 \cdot 71$; dinner, $r=0 \cdot 72$; fast food, $r=0 \cdot 46$; snacking, $r=0 \cdot 47$ ).

\section{Home food availability}

Participants were also asked to report the availability of healthy and unhealthy foods and drinks where they live. Response categories ranged from 1 (never available) to 4 (always available). A score for home food availability of healthy foods (range 5-20) was created by summing responses to five items that assessed the availability of: (i) fruits and vegetables at home; (ii) vegetables at dinner; (iii) fruit juice at home; (iv) milk at dinner; and (v) dark bread at home. A score for unhealthy food (range 4-16) was created by summing the home availability of four items: (i) 'junk food'; (ii) potato chips or other salty snack foods; (iii) chocolate or other candy; and (iv) soda pop. For both scales, higher numbers indicated higher availability of the food items assessed. These scales have been used in previous work and found to be predictive of young adults' food choices ${ }^{(19-21)}$.

\section{Sociodemographic characteristics}

Gender, age, parental status, race/ethnicity, SES and student status were self-reported on the Project EAT-II survey. Parental status was defined as having at least one child (yes/no), including stepchildren and adopted children. SES was based primarily on parental educational level, defined by the higher level of either parent at baseline ${ }^{(14)}$. Student status was defined as: not a student, student at a community or technical college (including full-time and part-time 2-year college students) or student at a 4 -year college.

\section{Statistical analyses}

Descriptive statistics were calculated to examine demographic and other characteristics of young adults by living situation. Given previous evidence documenting differences in diet-related factors between males and females at this age ${ }^{(22-24)}$, gender-stratified linear regression models were used to examine differences in meal frequency, dietary intake and home food availability outcomes according to living situation. Regression models were first examined unadjusted. Then a second model was examined 
adjusting for demographic variables (race/ethnicity, SES, age, parental status). Given our a priori hypothesis that sociodemographic differences exist across living situations (e.g. with lower SES groups and racial/ethnic minorities being more likely to live with their parents after high school), the purpose of these adjusted analyses was to assess whether or not there are disparities in dietary intake by living situation independent of these hypothesized differences in sociodemographic factors. These findings provide a valuable contrast to those of the unadjusted analyses, which serve primarily to identify which young adult subgroups may be most at risk and thus may be the most effective targets for intervention strategies. A 95\% confidence level was used to interpret the statistical significance of probability tests. Whenever the outcome variable exhibited positive skewness, testing was carried out under the square root transformation.

Participants were excluded from analyses if they did not complete the Project EAT-II survey ( $n$ 10) or the Youth and Adolescent FFQ at follow-up ( $n 5$ ) or if they reported a biologically implausible level of energy intake ( $n$ 8); a plausible range of $1 \cdot 7-29 \cdot 3 \mathrm{MJ}(400-7000 \mathrm{kcal})$ was selected a priori. Analyses were weighted to adjust for differential response rates to Project EAT-II using the response propensity method ${ }^{(25)}$, described in detail in a previous publication ${ }^{(13)}$. Analyses were conducted using the SAS statistical software package version $8 \cdot 2$ (SAS Institute, Cary, NC, USA).

\section{Results}

Significant differences $(P<0 \cdot 01)$ by living situation were observed for gender, SES, race/ethnicity, age and student status (Table 1). Males were more likely to be living with their parents, whereas a greater proportion of females were living in rented homes/apartments and/or living on campus. Lower SES and racial/ethnic minority groups were also more likely to be living with parents. Young adults living with their parents were more likely to be non-students or students attending a 2-year community or technical college.

Unadjusted analyses among young adult males and females indicated that across all types of living situations, dietary intake was generally not in line with the Dietary Guidelines for Americans $^{(26)}$ (see Tables 2 and 3). For both males and females, meal patterns differed by living situation, with those living on their own or with parents reporting eating meals (particularly breakfast and dinner) less frequently compared with those living on campus. Fast-food intake also differed by living situation, with the lowest frequencies being reported by those living on campus ( $P=0.02$ for males, $P<0.001$ for females).

Overall, young adults living with their parents and/or living in a rented apartment or house appeared to have poorer dietary intake than those living on campus. After adjusting for sociodemographic factors, females living on campus reported the highest intakes of fruit $(P=0 \cdot 003)$, vegetables $(P=0 \cdot 007)$, dark vegetables $(P<0 \cdot 001)$, Ca $(P=0.02)$ and whole grains $(P<0 \cdot 001)$, as well as the lowest percentage of energy from fat $(P<0 \cdot 001)$ and saturated fat $(P<0 \cdot 001)$. Results among males were observed in similar directions, although these differences were not statistically significant after controlling for sociodemographic factors. Among females, findings showed that on average females living with parents consumed more fast food and a greater percentage of energy from fat, as well as fewer whole grains and vegetables, compared with females living on their own in rented apartments and houses.

The availability of both healthy and unhealthy foods at home also differed by living situation among males and females. Adjusted analyses indicated that males and females living on campus reported the greatest availability of healthy foods where they lived $(P<0 \cdot 001)$, as

Table 1 Demographic and other characteristics of young adults by living situation: Project EAT (Eating Among Teens)-II, 2003-4

\begin{tabular}{|c|c|c|c|c|}
\hline & $\begin{array}{l}\text { \% Living in rented apartment or house } \\
\qquad(n 568)\end{array}$ & $\begin{array}{l}\text { \% Living with parents } \\
\qquad(n 796)\end{array}$ & $\begin{array}{l}\text { \% Living on campus } \\
\qquad(n 219)\end{array}$ & $P$ value \\
\hline \multicolumn{5}{|l|}{ Gender } \\
\hline Male $(n 705)$ & $32 \cdot 1$ & $55 \cdot 1$ & $12 \cdot 9$ & \multirow[t]{2}{*}{0.003} \\
\hline Female $(n 878)$ & $39 \cdot 0$ & $46 \cdot 5$ & $14 \cdot 6$ & \\
\hline \multicolumn{5}{|l|}{ Socio-economic status } \\
\hline Low $(n 564)$ & $35 \cdot 5$ & $58 \cdot 4$ & $6 \cdot 0$ & \multirow[t]{3}{*}{$<0.001$} \\
\hline Middle ( $n$ 792) & $34 \cdot 3$ & $50 \cdot 5$ & $15 \cdot 3$ & \\
\hline High (n 203) & $41 \cdot 8$ & $26 \cdot 8$ & $31 \cdot 4$ & \\
\hline \multicolumn{5}{|l|}{ Race } \\
\hline White ( $n$ 888) & $36 \cdot 6$ & $44 \cdot 1$ & $19 \cdot 3$ & \multirow[t]{4}{*}{$<0.001$} \\
\hline Black ( $n 255)$ & $44 \cdot 2$ & $50 \cdot 0$ & $5 \cdot 8$ & \\
\hline Asian ( $n$ 256) & $23 \cdot 9$ & $67 \cdot 7$ & $8 \cdot 4$ & \\
\hline Other ( $n$ 164) & $36 \cdot 8$ & $57 \cdot 7$ & $5 \cdot 5$ & \\
\hline \multicolumn{5}{|l|}{ Student status } \\
\hline Not a student $(n 568)$ & $38 \cdot 1$ & $61 \cdot 9$ & 0.0 & \multirow[t]{3}{*}{$<0.001$} \\
\hline 2-year college student ( $n$ 409) & $31 \cdot 2$ & $67 \cdot 8$ & $1 \cdot 0$ & \\
\hline 4-year college student ( $n$ 571) & $37 \cdot 5$ & $25 \cdot 4$ & $37 \cdot 1$ & \\
\hline Age (mean years, $n 1589$ ) & $20 \cdot 7$ & $20 \cdot 4$ & $20 \cdot 1$ & $<0.001$ \\
\hline
\end{tabular}

Mean estimates are unadjusted. Although the final sample size is 1687 , sample sizes of individual analyses vary slightly due to a small degree of missing data. 
Table 2 Mean meal frequencies, dietary intake and home food availability of young adult males by living situation: Project EAT (Eating Among Teens)-II, 2003-4

\begin{tabular}{|c|c|c|c|c|c|}
\hline & $\begin{array}{l}\text { Lives in rented apartment or house } \\
\qquad(n 226)\end{array}$ & $\begin{array}{l}\text { Lives with parents } \\
\qquad(n 388)\end{array}$ & $\begin{array}{l}\text { Lives on campus } \\
\qquad(n 91)\end{array}$ & $\begin{array}{l}\text { Crude } \\
P \text { value }\end{array}$ & $\begin{array}{l}\text { Adjusted }^{*} \\
P \text { value }\end{array}$ \\
\hline \multicolumn{6}{|l|}{ Meal frequency (per week) } \\
\hline Breakfast & $2 \cdot 7^{\mathrm{a}}$ & $3 \cdot 2^{\mathrm{b}}$ & $3 \cdot 5^{\mathrm{b}}$ & 0.004 & 0.004 \\
\hline Lunch & $5 \cdot 4$ & $5 \cdot 3$ & $5 \cdot 8$ & $0 \cdot 12$ & $0 \cdot 15$ \\
\hline Dinner & $6 \cdot 1^{\mathrm{a}}$ & $6 \cdot 1^{\mathrm{a}}$ & $6 \cdot 5^{\mathrm{b}}$ & 0.05 & 0.26 \\
\hline Snacks & $1 \cdot 6$ & $1 \cdot 7$ & $1 \cdot 7$ & 0.46 & 0.49 \\
\hline Fast food & $2 \cdot 3^{\mathrm{a}}$ & $2 \cdot 2^{\mathrm{a}}$ & $1 \cdot 7^{\mathrm{b}}$ & 0.02 & 0.04 \\
\hline \multicolumn{6}{|c|}{ Dietary intake (mean servings, unless otherwise indicated) } \\
\hline Fruit & 1.6 & $1 \cdot 7$ & $1 \cdot 7$ & $0 \cdot 74$ & 0.44 \\
\hline Vegetables & $1 \cdot 5^{\mathrm{a}, \mathrm{b}}$ & $1 \cdot 4^{\mathrm{a}}$ & $1 \cdot 6^{b}$ & 0.04 & $0 \cdot 19$ \\
\hline Dark vegetables & $0 \cdot 3$ & $0 \cdot 3$ & $0 \cdot 4$ & 0.06 & $0 \cdot 16$ \\
\hline Ca-rich foods & $3 \cdot 1^{a, b}$ & $2 \cdot 9^{a}$ & $3 \cdot 3^{\mathrm{b}}$ & 0.02 & 0.62 \\
\hline $\mathrm{Ca}(\mathrm{mg})$ & $1044^{\mathrm{a}, \mathrm{b}}$ & $990^{\mathrm{a}}$ & $1152^{b}$ & 0.02 & 0.39 \\
\hline Whole grains & 0.9 & 0.9 & $1 \cdot 0$ & 0.45 & 0.57 \\
\hline Energy (MJ) & $8 \cdot 9$ & $8 \cdot 5$ & $9 \cdot 1$ & $0 \cdot 14$ & 0.65 \\
\hline Energy (kcal) & 2121 & 2030 & 2172 & $0 \cdot 14$ & 0.65 \\
\hline$\%$ Energy from fat & $31 \cdot 3$ & $31 \cdot 0$ & $30 \cdot 8$ & 0.62 & 0.74 \\
\hline$\%$ Energy from saturated fat & $11 \cdot 0$ & $10 \cdot 9$ & $10 \cdot 7$ & 0.50 & 0.43 \\
\hline Soft drinks & $1 \cdot 3$ & $1 \cdot 4$ & $1 \cdot 2$ & $0 \cdot 14$ & 0.08 \\
\hline \multicolumn{6}{|l|}{ Home food availability } \\
\hline Healthy (range: 5-20) & $14 \cdot 1^{\mathrm{a}}$ & $14 \cdot 9^{b}$ & $15 \cdot 9^{c}$ & $<0.001$ & $<0.001$ \\
\hline Unhealthy (range: 4-16) & $11 \cdot 1^{a, b}$ & $10 \cdot 8^{a}$ & $11 \cdot 5^{\mathrm{b}}$ & 0.05 & $0 \cdot 16$ \\
\hline
\end{tabular}

Mean estimates are unadjusted. Although the final sample size is 705 , sample sizes of individual analyses vary slightly due to a small degree of missing data. $a, b, c$ Mean values with unlike superscript letters were significantly different in the unadjusted model $(P<0 \cdot 05)$. Only presented for unadjusted models in which living situation was statistically significant.

${ }^{*}$ Adjusted for race/ethnicity, socio-economic status, age and parental status (i.e. if participant has children).

Table 3 Mean meal frequencies, dietary intake and home food availability of young adult females by living situation: Project EAT (Eating Among Teens)-II, 2003-4

\begin{tabular}{|c|c|c|c|c|c|}
\hline & $\begin{array}{l}\text { Lives in rented apartment or house } \\
\qquad(n 342)\end{array}$ & $\begin{array}{l}\text { Lives with parents } \\
\qquad(n 408)\end{array}$ & $\begin{array}{l}\text { Lives on campus } \\
\qquad(n 128)\end{array}$ & $\begin{array}{l}\text { Crude } \\
P \text { value }\end{array}$ & $\begin{array}{c}\text { Adjusted }^{*} \\
P \text { value }\end{array}$ \\
\hline \multicolumn{6}{|l|}{ Meal frequency (per week) } \\
\hline Breakfast & $3 \cdot 3^{\mathrm{a}}$ & $3 \cdot 0^{\mathrm{a}}$ & $4 \cdot 4^{\mathrm{b}}$ & $<0.001$ & $<0.001$ \\
\hline Lunch & $5 \cdot 2^{\mathrm{a}}$ & $5 \cdot 0^{\mathrm{a}}$ & $5 \cdot 7^{b}$ & 0.002 & $0 \cdot 10$ \\
\hline Dinner & $5 \cdot 6^{\mathrm{a}}$ & $5 \cdot 9^{\mathrm{a}}$ & $6 \cdot 2^{b}$ & 0.002 & 0.02 \\
\hline Snacks & $1 \cdot 6$ & $1 \cdot 8$ & $1 \cdot 7$ & 0.67 & $0 \cdot 41$ \\
\hline Fast food & $1 \cdot 7^{\mathrm{a}}$ & $1 \cdot 9^{b}$ & $1 \cdot 2^{\mathrm{c}}$ & $<0.001$ & 0.01 \\
\hline \multicolumn{6}{|c|}{ Dietary intake (mean servings, unless otherwise indicated) } \\
\hline Fruit & $1 \cdot 6^{\mathrm{a}}$ & $1 \cdot 6^{\mathrm{a}}$ & $1 \cdot 9^{b}$ & $<0.001$ & 0.003 \\
\hline Vegetables & $1 \cdot 8^{\mathrm{a}}$ & $1 \cdot 6^{\mathrm{a}}$ & $2 \cdot 0^{\mathrm{b}}$ & $<0.001$ & 0.007 \\
\hline Dark vegetables & $0 \cdot 5^{\mathrm{a}}$ & $0 \cdot 4^{\mathrm{b}}$ & $0 \cdot 6^{\mathrm{C}}$ & $<0.001$ & $<0.001$ \\
\hline Ca-rich foods & $2 \cdot 4^{\mathrm{a}}$ & $2 \cdot 2^{\mathrm{a}}$ & $2 \cdot 9^{\mathrm{b}}$ & $<0.001$ & $0 \cdot 13$ \\
\hline Calcium (mg) & $837^{\mathrm{a}}$ & $785^{\mathrm{a}}$ & $1021^{\mathrm{b}}$ & $<0.001$ & 0.02 \\
\hline Whole grains & $0 \cdot 8^{\mathrm{a}}$ & $0 \cdot 7^{\mathrm{b}}$ & $1 \cdot 0^{\mathrm{c}}$ & $<0.001$ & $<0.001$ \\
\hline Energy (MJ) & $7 \cdot 1$ & $7 \cdot 1$ & $7 \cdot 5$ & 0.11 & 0.25 \\
\hline Energy (kcal) & 1691 & 1698 & 1804 & $0 \cdot 11$ & 0.25 \\
\hline$\%$ Energy from fat & $28 \cdot 8^{a}$ & $30 \cdot 0^{\mathrm{b}}$ & $27 \cdot 0^{c}$ & $<0.001$ & $<0.001$ \\
\hline$\%$ Energy from saturated fat & $9 \cdot 8^{a}$ & $10 \cdot 4^{b}$ & $9 \cdot 1^{\mathrm{c}}$ & $<0.001$ & $<0.001$ \\
\hline Soft drinks & $1 \cdot 1$ & $1 \cdot 2$ & $1 \cdot 0$ & 0.09 & 0.02 \\
\hline \multicolumn{6}{|l|}{ Home food availability } \\
\hline Healthy (range: 5-20) & $14 \cdot 5^{\mathrm{a}}$ & $14 \cdot 6^{a}$ & $15 \cdot 9^{b}$ & $<0.001$ & $<0.001$ \\
\hline Unhealthy (range: $4-16$ ) & $10 \cdot 6^{a}$ & $10 \cdot 9^{a}$ & $11 \cdot 7^{b}$ & $<0.001$ & 0.01 \\
\hline
\end{tabular}

Mean estimates are unadjusted. Although the final sample size is 878 , sample sizes of individual analyses vary slightly due to a small degree of missing data. $\mathrm{a}, \mathrm{b}, \mathrm{c}$ Mean values with unlike superscript letters were significantly different in the unadjusted model $(P<0 \cdot 05)$. Only presented for unadjusted models in which living situation was statistically significant.

${ }^{*}$ Adjusted for race/ethnicity, socio-economic status, age and parental status (i.e. if participant has children).

well as the greatest availability of unhealthy foods (statistically significant among females only, $P=0 \cdot 01 ; P=0 \cdot 16$ for males).

Overall, despite adjusting for sociodemographic covariates in our models, where differences across living situation were shown to exist (Table 1), a majority of the differences detected in unadjusted models remained significant (sixteen of the twenty-two crude associations that were significant, across both genders). Adjusting for sociodemographic factors appeared to result in greater attenuation of estimates among males compared with females. 


\section{Discussion}

The findings from the present study showed that young adults living with their parents and those living on their own (i.e. in rented apartments or houses) exhibited the poorest dietary intake. These patterns were evident even after adjusting for sociodemographic characteristics such as race/ethnicity, SES and age. In contrast, young adults living on college and university campuses reported the most favourable diet and meal patterns. Since a large proportion of students living on campus may participate in some type of structured meal plan or other food service option, it is likely that this consistent, institutional meal provision could play an important role in providing access to an abundant array of healthy foods ${ }^{(7)}$. In general, post-secondary institutional food service is common on college and university campuses in the USA, but may vary substantially across other international settings. Our findings suggest that without college food service providing consistent and readily accessible meals, dietary quality among US young adults might be substantially lower.

Our findings are consistent with previous research illustrating poor dietary intake among young adults who have begun to live on their own and are responsible for their own meal provision and food acquisition for the first time in their lives ${ }^{(7,8,27)}$. Previous research from Project EAT has indicated that many young adults at this age are ill-prepared for home meal preparation and lack the skills and/or the resources to regularly prepare food at home $^{(28)}$, and have a high propensity for 'eating on the run' rather than eating in more traditional meal settings. These factors have been associated with poor diet quality among young adults ${ }^{(28)}$ and are likely linked to characteristics of one's living situation.

Our findings may not only have important implications for young adults moving out on their own for the first time, but also for young adults continuing to live with their parents after high school. For example, previous research in the USA ${ }^{(7,8,27)}$ and in other countries ${ }^{(29-31)}$ suggests that young adults either living on post-secondary campuses or continuing to live with their parents may experience benefits in terms of both nutrition and weight status compared with those young adults who are living independently. However, a major limitation of these previous studies is their focus on traditional college students and their failure to capture a young adult population representing a range of lifestyle characteristics. In contrast, the findings presented in the current paper are drawn from a population-based sample of young adults, including both those who attend college and those who do not. Results from our young adult cohort suggest that those individuals continuing to live with their parents may not be exhibiting as favourable diet-related profiles as previous research might imply ${ }^{(29,30)}$. These findings may reflect heightened levels of away-from-home food consumption for those living in their parents' homes, possibly due to greater scheduling demands from work and/or school, or greater discretionary income due to living at home, although the factors underlying these differences are not clear. Baseline disparities in dietary intake among families may also account for these trends of poor diet quality among young adults living with their parents, even after adjusting for SES and racial/ethnic differences. Future longitudinal research exploring these issues is needed.

Given that a growing number of young adults live with their parents after graduating from high school ${ }^{(32)}$, it is important to understand how family dynamics and mealrelated influences change during the pre-high school to post-high school years. Although previous research has suggested that living with one's parents after high school may limit some types of young adult risk behaviours (e.g. alcohol and drug use) ${ }^{(33)}$, other risk behaviours - such as poor dietary patterns - may increase, particularly as young adults adopt busier schedules and begin to turn to convenience and fast foods as a replacement for home meal preparation. While previous research among college students has suggested that young adults still living at home with their parents after high school may be engaging in healthy eating behaviours due to home- and family-related factors (e.g. less responsibility for purchasing food for themselves and/or preparing meals), our data do not support this assertion.

To our knowledge, this is the first study of its kind to compare dietary factors across living situations drawing from such a diverse, young adult cohort. An additional strength of the present study includes the collection of data on a broad array of meal- and diet-related factors. Despite these strengths, our findings should be interpreted with several caveats in mind. For example, our cross-sectional sample was drawn from a large, longitudinal cohort study consisting of individuals who had been high school students in one Midwestern metropolitan area in 1998-9, which may limit generalizability. Furthermore, our self-reported dietary data were collected using an FFQ. While validated food frequency tools are a well-recognized method for dietary assessment in large-scale studies, it can be difficult to accurately estimate intake frequency and serving sizes with a limited number of response options. In general, the nature of the self-reported measures used here, as well as the crosssectional design, may also limit the conclusions one can draw from these results. Finally, although our analyses adjusted for important sociodemographic factors such as SES, it is possible that these factors have not been fully captured using the covariates available in our data and that residual confounding may be resulting in some of the differences observed between living situations in adjusted models.

In conclusion, our findings indicate that those young adults living on their own and with their parents report 
less frequent meals and poorer dietary intakes compared with those living on campus. Despite the disparities in diet by living situation, it is important to recognize that overall few young people at this age are consuming optimal diets. Although students living on campus reported the best overall dietary intake, they were, on average, far from meeting national health recommendations (e.g. consuming only $1 \cdot 6-2 \cdot 0$ servings of vegetables and $1 \cdot 0$ serving of whole grains daily) ${ }^{(26,34)}$. While college food service and meal plans may be an important environmental influence that effectively improves the quality of dietary intake among many young adults living on post-secondary campuses, these findings overall suggest that effective health promotion efforts are needed for all young adults across a variety of living situations.

Little research to date has sought to understand the lifestyle characteristics of emerging adults. Additional work is needed to explore the modifiable determinants, environmental influences and broader lifestyle characteristics influencing dietary intake among this age group, particularly among those who are still living with their parents and those who have recently begun to live independently. Such work will inform the development of intervention strategies promoting healthy dietary intake and overall wellness during this important age in a wide range of settings. Ultimately, as young adults begin to lead independent lives outside the previous constraints of their family home, the health behaviours followed during this period may set the stage for establishing longterm behaviours that have an important impact on lifetime disease risk. Given that poor dietary intake is one of the leading modifiable contributors to mortality and that behaviours during young adulthood may have long-term impacts on chronic disease risk, nutrition promotion among emerging adults is an important focal area for future research ${ }^{(35)}$.

\section{Acknowledgements}

Project EAT was supported by Grant R40 MC 00319 from the Maternal and Child Health Bureau (Title V, Social Security Act), Health Resources and Services Administration, Department of Health and Human Services. Additional salary support for the analysis of these data was also provided by Award Number K07CA126837 from the National Cancer Institute. The content of this manuscript is solely the responsibility of the authors and does not necessarily represent the official views of the National Cancer Institute or the National Institutes of Health. There are no conflicts of interest. All authors were responsible for interpreting results and revising the manuscript. M.C.N. wrote the manuscript and developed the analysis plan. N.I.L. conducted the statistical analysis. D.N.-S. and M.S. designed the Project EAT study and were responsible for data collection.

\section{References}

1. Nelson M, Story M, Larson N, Neumark-Sztainer D \& Lytle L (2008) Emerging adulthood and college-aged youth: an overlooked age for weight-related behavior change. Obesity (Silver Spring) 16, 2205-2211.

2. Park MJ, Paul Mulye T, Adams SH, Brindis CD \& Irwin CE Jr (2006) The health status of young adults in the United States. J Adolesc Health 39, 305-317.

3. Green MP, McCausland KL, Xiao H, Duke JC, Vallone DM \& Healton CG (2007) A closer look at smoking among young adults: where tobacco control should focus its attention. Am J Public Health 97, 1427-1433.

4. Gordon-Larsen P, Adair LS, Nelson MC \& Popkin BM (2004) Five-year obesity incidence in the transition period between adolescence and adulthood. Am J Clin Nutr 80, 569-575.

5. Norman JE, Bild D, Lewis CE, Liu K \& West DS (2003) The impact of weight change on cardiovascular disease risk factors in young black and white adults: the CARDIA study. Int J Obes Relat Metab Disord 27, 369-376.

6. Carnethon MR, Loria CM, Hill JO, Sidney S, Savage PJ \& Liu K (2004) Risk factors for the metabolic syndrome: the CARDIA study, 1985-2001. Diabetes Care 27, 2707-2715.

7. Brown LB, Dresen RK \& Eggett DL (2005) College students can benefit by participating in a prepaid meal plan. $J \mathrm{Am}$ Diet Assoc 105, 445-448.

8. Brunt AR \& Rhee YS (2008) Obesity and lifestyle in US college students related to living arrangements. Appetite 51, 615-621.

9. Fulkerson JA, Nelson MC, Lytle LA, Moe SG, Heitzler C \& Pasch KE (2008) The development and validation of a comprehensive home food inventory. Int J Behav Nutr Phys Act 5, 55.

10. Lytle LA, Kubik MY, Perry C, Story M, Birnbaum AS \& Murray DM (2006) Influencing healthful food choices in school and home environments: results from the TEENS study. Prev Med 43, 8-13.

11. Campbell KJ, Crawford DA, Salmon J, Carver A, Garnett SP \& Baur LA (2007) Associations between the home food environment and obesity-promoting eating behaviors in adolescence. Obesity (Silver Spring) 15, 719-730.

12. Neumark-Sztainer D, Hannan PJ, Story M, Croll J \& Perry C (2003) Family meal patterns: associations with sociodemographic characteristics and improved dietary intake among adolescents. J Am Diet Assoc 103, 317-322.

13. Neumark-Sztainer D, Wall M, Guo J, Story M, Haines J \& Eisenberg M (2006) Obesity, disordered eating, and eating disorders in a longitudinal study of adolescents. J Am Diet Assoc 106, 559-568.

14. Neumark-Sztainer D, Story M, Hannan PJ \& Croll J (2002) Overweight status and eating patterns among adolescents: where do youths stand in comparison with the Healthy People 2010 objectives? Am J Public Health 92, 844-851.

15. Rockett HR, Breitenbach M, Frazier AL, Witschi J, Wolf AM, Field AE \& Colditz GA (1997) Validation of a youth/ adolescent food frequency questionnaire. Prev Med 26, 808-816.

16. Rockett HR, Wolf AM \& Colditz GA (1995) Development and reproducibility of a food frequency questionnaire to assess diets of older children and adolescents. J Am Diet Assoc 95, 336-340.

17. Perks SM, Roemmich JN, Sandow-Pajewski M, Clark PA, Thomas E, Weltman A, Patrie J \& Roqol AD (2000) Alterations in growth and body composition during puberty. IV. Energy intake estimated by the youth-adolescent food-frequency questionnaire: validation by the doubly labeled water method. Am J Clin Nutr 72, 1455-1460. 
18. Larson NI, Neumark-Sztainer D, Hannan PJ \& Story M (2007) Trends in adolescent fruit and vegetable consumption, 1999-2004: Project EAT. Am J Prev Med 32, 147-150.

19. French SA, Story M, Neumark-Sztainer D, Fulkerson JA \& Hannan P (2001) Fast food restaurant use among adolescents. Int J Obes Relat Metab Disord 25, 1823-1833.

20. Boutelle K, Fulkerson J, Neumark-Sztainer D, Story M \& French S (2007) Fast food for family meals: relationships with parent and adolescent food intake, home food environment and weight status. Public Health Nutr 10, 16-23.

21. Larson NI, Neumark-Sztainer DR, Harnack LJ, Wall MM, Story MT \& Eisenberg ME (2008) Fruit and vegetable intake correlates during the transition to young adulthood. $A m \mathrm{~J}$ Prev Med 35, 33-37.

22. Larson NI, Neumark-Sztainer DR, Story MT, Wall MM, Harnack LJ \& Eisenberg ME (2008) Fast food intake: longitudinal trends during the transition to young adulthood and correlates of intake. J Adolesc Health 43, 79-86.

23. Larson NI, Neumark-Sztainer D, Hannan PJ \& Story M (2007) Family meals during adolescence are associated with higher diet quality and healthful meal patterns during young adulthood. J Am Diet Assoc 107, 1502-1510.

24. Davy SR, Benes BA \& Driskell JA (2006) Sex differences in dieting trends, eating habits, and nutrition beliefs of a group of midwestern college students. I Am Diet Assoc 106, 1673-1677.

25. Little R (1986) Survey nonresponse adjustments for estimates of means. Int Stat Rev 54, 137-139.

26. US Department of Health and Human Services \& US Department of Agriculture (2005) Dietary Guidelines for Americans, 2005, 6th ed. Washington, DC: US Government Printing Office.
27. Brevard PB \& Ricketts CD (1996) Residence of college students affects dietary intake, physical activity, and serum lipid levels. I Am Diet Assoc 96, 35-38.

28. Larson NI, Story M, Eisenberg ME \& Neumark-Sztainer D (2006) Food preparation and purchasing roles among adolescents: associations with sociodemographic characteristics and diet quality. J Am Diet Assoc 106, 211-218.

29. Suzuki M, Murashima M \& Hoerr S (2007) Body mass and fatness of Japanese college women and relationship to place of residence. Nutr Diet 64, 159-164.

30. Papadaki A, Hondros G, Scott JA \& Kapsokefalou M (2007) Eating habits of university students living at, or away from home in Greece. Appetite 49, 169-176.

31. Kremmyda LS, Papadaki A, Hondros G, Kapsokefalou M \& Scott JA (2008) Differentiating between the effect of rapid dietary acculturation and the effect of living away from home for the first time, on the diets of Greek students studying in Glasgow. Appetite 50, 455-463.

32. Matsudaira J (2007) Economic Conditions and the Living Arrangements of Young Adults. Working Paper. Philadelphia, PA: MacArthur Network on Transitions to Adulthood.

33. White HR, McMorris BJ, Catalano RF, Fleming CB, Haggerty KP \& Abbott RD (2006) Increases in alcohol and marijuana use during the transition out of high school into emerging adulthood: the effects of leaving home, going to college, and high school protective factors. I Stud Alcobol 67, 810-822.

34. US Department of Agriculture (2009) MyPyramid. http:// www.mypyramid.gov/ (accessed July 2009).

35. Mokdad AH, Marks JS, Stroup DF \& Gerberding JL (2004) Actual causes of death in the United States, 2000. JAMA 291, 1238-1245. 